\title{
LAS BOLSAS GEREMONIALES EN EL ARTE MESOAMERICANO
}

\section{Nelly GutíérRez Solana}

En este artículo me ocuparé de la antigüedad de las bolsas, el ámbito geográfico en el cual aparecen, los tipos de bolsas representados y de sus posibles significados como objetos culturales.

El hecho de que las bolsas ceremoniales aparezcan desde el primer estilo artístico prehispánico, el olmeca, hasta el último gxan estilo, el mexica, indica la gran importancia que tenían. Su importancia queda demostrada también por su amplia difusión, ya que se usaron en las principales regiones mesoamericanas: el altiplano, la región oaxaqueña, la región de la Costa del Golfo y la región maya.

En las representaciones de las bolsas podemos observar lo variado que eran los materiales empleados para hacerlas. Se trata de materiales flexibles y perecederos, por lo cual no han llegado hasta nosotros ejemplos importantes de este tipo de objetos. Entre los materiales que pueden haberse empleado están los siguientes: papel, cuero, tela, petatillo, y se adomaban con cuexdas y plumas, principalmente.

¿Qué tipo de personajes son los que portan las bolsas ceremoniales? Son personajes que por su atavío y por la importancia que se les da en las artes deben de haber pertenecido a la clase elitista. En Teotihuacan se pintaron individuos con un vestuario elaborado que esparcen semillas al mismo tiempo que entonan oraciones para lograr la fertilidad; por tanto, es probable que se trate de sacerdotes, y aunque tradicionalmente se ha creido que llevan copal en las bolsas es posible pensar que guardarían semillas en ellas, precisamente por la actividad que desempeñan. En el mural del pórtico 3 del Palacio de Zacuala, un hombre portador de una bolsa carga en la espalda una canasta con mazorcas y maíz; puede tratarse también de un sacerdote asociado al culto agrícola. En la siguiente cultura importante del altiplano, la tolteca, encontramos que son las cariátides monumentales las que presentan bolsas cuya forma es muy distinta a las teotihuacanas. Es difícil saber para qué empleaban las bolsas, pero es el único objeto que llevan que no está asocialo con la guerra. En los códices del Posclásico Tardío de la misma región, como son los del Grupo Borgia, los personajes que ostentan bolsas también cogen los instrumentos empleados en el auto-sacrificio, como son las púas y los huesos; esto significa que son los sacerdotes 
quienes practicaban asiduamente este tipo de penitencia los que sostienen las bolsas. La identificación como sacerdotes es aún más clara si consideramos que Quetzalcóatl, el dios sacerdote por excelencia, es quien aparece casi siempre con una bolsa. Un tipo de bolsa, el copalxiquipilli, sabemos, por las fuentes, que se utilizaba para guardar el copal, resina olorosa que acompañaba a los diversos rituales. En la Costa del Golfo y en la región oaxaqueña, los portadores de bolsas ostentan atavios que indican su alta posición dentro de la sociedad, pero no hay mayores datos para saber con exactitud el papel que desempeñaban dentro de la misma. Los dignatarios mayas en varias estelas portan bolsas le hermosos diseños.

En seguida describiré los tipos principales de bolsas.

En el monumento 19 de La Venta, un personaje recargado sobre una gran serpiente coge, por medio de un asa, una bolsa sencilla de forma aproximadamente rectangular (lámina 1-a). En la misma zona de la Costa del Golfo, ya en el periodo clásico, se observan bolsas en los sitios de El Tajín, Gerro de las Mesas y en Las Higueras. El tipo de bolsa que encontramos en cada uno de estos lugares es diferente. En una escultura de la Pirámide de los Nichos de El Tajín, aparece una bolsa grande de contorno inferior curvo que parece tener tres elementos anudados en su extremo superior y una pluma en el inferior (lámina 1-b); hay otra parecida con cuerdas entrelazadas al centro (lámina 1-c). La bolsa esculpida en la estela 4 de Cerro de las Mesas muestra elementos anudados en sus extremos superior e inferior y de ella cae un elemento alargado terminado en punta (lámina 1-ch). En Las Higueras se representaron dos bolsas, ambas de forma rectangular y con franjas colgantes (láminas $1-d$ y $1-e)$.

Las bolsas de Teotihuacan se caracterizan por su mayor eleboración. Siempre se les representan claramente las asas y es común que tengan elementos anudados en sus contornos superiores. Hay un tipo especialmente interesante pintado en Tepantitla. Se nota que se compone de variados elementos: bordes aserrados, franjas horizontales y pequeñas figuras zoomorfas. En dos casos se presentan las cabezas y patas delanteras de lo que podrían ser coyotes (láminas 2-a y 2-b), mientras que en otra se asoma la cabeza de un animal o de un pez. En el mural 3 del pórtico 1 de Tetitla parece ser un jaguar el que se asoma de una bolsa (lámina 2-ch). Estas bolsas deben de haber requerido de un gran trabajo para hacerlas además del uso de numerosos materiales. En otras 
bolsas teotihuacanas menos elaboradas se desprenden franjas con pequeñas líneas en su interior; posiblemente se quiso dar la idea de que se trataba de la piel de un animal empleada para decorarlas (láminas 2-d y $2-e)$.

Las bolsas que aparecen en el arte zapoteco varían del tipo más sencillo al más elaborado. En dos casos tenemos bolsas muy semejantes a la que se pintó en un mural de Zacuala en Teotihuacan, lo cual parece indicar que se trata de personajes teotihuacanos de visita en Monte Albán; estos dos casos son la lápida de Bazán (lámina 2-f) y la llamada estela lisa. En la primera es sobre todo evidente la semejanza, pues el interior se decoró con un elemento terminado en dos volutas al igual que en Zacuala. Una bolsa también con elementos anudados en la parte superior y con dos volutas se labró en un relieve de Macuilxóchitl, en el valle de Oaxaca (lámina 2-h). En la tumba 104 de Monte Albán se pintó una bolsa con un elemento colgante, la cual tiene, en su parte superior, dos elementos ovalados unidos por uno rectangular (lámina 2-g). El tipo más sencillo puede observarse en la tumba 1 de Zaachila de forma muy alargada (lámina 2-i).

Las bolsas representadas en el arte maya muestran riqueza en sus disenos decorativos. Proskouriakoff, en su libro A Study of Classic Maya Sculpture, establece una secuencia temporal paxa las mismas. Según la autora, en una época temprana hay sólo un elemento anudado en la par-. te superior (láminas $3 \mathrm{a}$-c); posteriormente aparecen dos, uno en la parte superior y uno en el inferior, además a las bolsas se les adorna con varios diseños y terminan en una orilla ornamental (láminas $3 \mathrm{ch}-\mathrm{e}$ ). "Después del siglo vir es común que se decore la sección de abajo con crótalos de serpiente (láminas 3 f y g) y en una época más tardía terminan generalmente en una voluta grande" (láminas h-j). ${ }^{1}$

Las bolsas son sobre todo importantes en los sitios de Tikal, Naranjo, Piedras Negras y Bonampak. Como son los gobernantes los que las llevan, es posible pensar que éstos tenían tanto un poder religioso como secular 0 , menos probablemente, que las bolsas ya se identificaban con el poder civil. Quizá la existencia de las bolsas en el ámbito maya se deba a una influencia teotihuacana, aunque el parecido entre las bolsas de los dos sitios se limita al elemento anudado en la parte superior y a un elemento colgante de la parte inferior, tal como aparece en la bolsa pintada en el patio norte de la plaza de la Pirámide del Sol (2 -d). Tam-

1 Proskouriakoff, $1950, \mathrm{p} 89$ 
bién la idea de decorar las bolsas con figuras zoomorfas puede ser influencia teotihuacana, aunque en Teotihuacan aparecen en la parte central de las mismas y en la zona maya están en la parte superior. Merle Green en su comentario a la estela 2 de Bonampak ${ }^{2}$ menciona al apéndice con crótalos como un rasgo foráneo a lo maya; hay que aclarar, sin embargo, que en Teotihuacan no se representan crótalos en ias bolsas, aunque sí aparecen en los murales como en el cuarto 2 de Tepantitla.

Entre los elementos decorativos de las bolsas mayas que mexecen especialmente nuestra atención tenemos los siguientes: la estela 13 de Piedras Negras, cuya bolsa lleva el glifo 13 ahau; la bolsa de la estela 18 de Yaxchilán con la cara de Tláloc, por lo cual puede pensarse en una influencia teotihuacana (lámina 3-k); la estela 2 de Bonampak con un jaguarcito en la parte superior; la estela 3 del mismo lugar con una serpiente también en la parte superior (lámina 3-1), y la estela 2 de Aguateca con una cabeza de jaguar arriba de la bolsa.

Una bolsa de gran tamaño se labró en la estela 1 de Seibal, fechada en 869 d. C., y de ella se desprenden grandes volutas (lámina 9-i). El asa, bastante grande, está representada claramente y en el interior de la parte rectangular de la bolsa tiene diseños curvilíneos; a un lado de la bolsa, quizá como parte de su decoración, hay una serpiente con la boca abierta.

En el altiplano, en el Posclásico Temprano tenemos un tipo de bolsa tatalmente diferente al teotihuacano, lo cual indica una tradición diferente; me refiero a las bolsas que portan las cariátides de Tula. Estas bolsas son de sección circular, no llevan elementos anudados ni colgantes y se ornamentan con grecas escalonadas (lámina 4-a).

Dentro de la misma región del altiplano son de interés las bolsas dibujadas en Ios códices del Posclásico Tardío. Hay una forma que es la más común aunque también aparecen otras. Esta forma más común semeja una "u" con una serie de divisiones internas paralelas al contorno exterior. Tiene una franja arriba de la que caen borlas con colgajos; además del extremo inferior de la bolsa se desprenden otros dos elementos alargados. Este tipo de bolsa se pintó en las láminas 18, 19, 30 y 35 del Códice Borgia, entre otras. Los colores empleados son el gris, el blanco, el negro y el rojo (lámina 4-b). Pero, como se dijo anteriormente, hay otras distintas como la de la lámina 23 de dicho

2 Green, Rands y Graham, 1972. 
códice en la cual se dibujó a Tonatiuh con una bolsa de asa alargada y de forma rectangular con la típica decoración mexica de pequeños rectángulos con círculos en sus centros y de la que caen cintas (láminas 4-c). En el Códice Cospi también encontramos una bolsa rectangular con cuadros concéntricos en su interior y colgajos en su borde inferior (lámina 4-ch). En la lámina xuI del Códice Laud hay una mujer con espinas y un hueso en una mano y en la otra una bolsa que cuelga de cintas muy alargadas; aquí encontramos la asociación que mencioné anteriormente, entre los instrumentos del autosacrificio y las bolsas (lámina 4-d).

Dentro de la tradición mexica, el Códice Borbónico muestra un tipo común de bolsa que puede observarse en las láminas 7, 12, 16 y 18, entre otras. Su forma es redondeada con colgajos en sus extremos superiores y en su base y, en general, recuerda bastante a las bolsas del Códice Borgia, sobre todo en los elementos colgantes. Rasgo peculiar de las bolsas del Códice Borbónico es la cruz de brazos iguales que decora su interior. Estas bolsas se dejan en blanco y sólo los contornos se pintan de negro. En algunos ejemplares es de interés que se dibuja parte de su contenido, como en la lámina 16 en la que se asoma la cabeza de una serpiente (lámina 4-e), o en la lámina 20 en la que se observa el extremo superior de un fémur y la representación estilizada de una flor (lámina 4-f). Por estos dibujos del Códice Borbónico nos damos cuenta de que no sólo se guardaba el copal en ellas, sino también los instrumentos del autosacrificio y otros objetos variados. Bolsas distintas a este tipo usual se encuentran en la lámina 30 del mismo códice, lámina que representa una escena de la fiesta de Ochpaniztli. Estas bolsas se pintaron de diferentes colores según el color de los atavios de los personajes que las ostentan; su forma es trapezoidal con tiras rectangulares a los lados. Dan la impresión de ser más planas que las de sección circular y probablemente servían para llevar los granos de maíz que se esparcían en esta fiesta (lámina 4-g).

En los códices pintados en la época colonial, como el Vaticano $A$, el Telleriano Remensis, el Tonalámatl de Aubin, el Magliabecchi y el Mendocino se continúa la representación de las bolsas y pueden observarse tanto el tipo más redondeado como el aplanado. En los primeros dos códices se dibujaron bolsas muy parecidas al Borbónico (láminas 5a y 5b). Es de interés que, sobre todo en el Mendocino, se emplea la bolsa con un significado numérico ya que su presencia junto a ciertos objetos indica la cantidad de ocho mil (lámina 5 f) . En el Códice Magliabecchi 
hay varias del tipo aplanado decoradas en forma diversa (láminas 5 ch-e). En el Códice Matritense, el personaje sahumador de pie sobre el basamento situado frente al Templo Mayor lleva su bolsita para identificarlo claramente como integrante de la clase sacerdotal.

Las bolsas talladas en los relieves mexicas son diferentes a las pintadas en los códices, quizá porque estas últimas pertenecen a la tradición que se remonta a los códices del Grupo Borgia mientras que la de los relieves han de haberse copiado de objetos usados realmente por los gobernantes y cuyas formas eran novedosas. En la famosa lápida de la dedicación del Templo Mayor, los sumos gobernantes llevan bolsas quizá como símbolo de su poder religioso; las bolsas son de forma aproximadamente rectangular con una franja superior con flecos y un elemento colgante. Como rasgo novedoso presentan tres círculos en sus interiores (lámina 5-j). En dos cajas de piedra pertenecientes a la cultura mexica, aparecen personajes que portan bolsas aunque su forma es distinta. La conservada en el Museo Nacional de Antropología tiene una serie de divisiones internas como si se tratara de una bolsa tejida, además de tres cuentas donde se une el asa al cuerpo de la bolsa (lámina 5-1). En la caja del Museum of the American Indian, la bolsa se compone de tres elementos colgantes (lámina 5 -m). En la escultura conocida como El Teocalli de la Guerra Sagrada, los personajes de los lados, ya se trate de dioses o de sacerdotes personificadores de ellos, llevan lo que parecen ser bolsas formadas por dos elementos ovales unidos por flecos que presentan a los lados elementos colgantes (lámina $5 k$ ).

Por último, en los códices de la región mixteca también encontramos un tipo de bolsa que se repite muchas veces (entre otras las láminas 4, 15, 16 y 35, del Nuttall). Es parecida a las del Códice Borgia porque al igual que en ellas tiene colgajos a ambos lados y también en su extremo inferior, pero la diferencia principal consiste en que el tipo mixteco tiene una forma más ovalada. El color usado en estos códices es el verde, el café y en algunos casos se deja en blanco (láminas 5-g y 5-i).

En resumen podemos decir que las bolsas fueron comunes en las principales regiones de Mesoamérica desde la civilización más temprana, la olmeca, hasta el Posclásico Tardío. Quizá de Teotihuacan pasó a la región zapoteca y a la maya. Es un objeto relacionado sobre todo al sacerdocio y cuando la llevan los gobernantes, como entre los mayas y los mexicas, puede indicar que aunaban el poder religioso al civil. Las formas de las bolsas son variadas pero para el Posclásico Tardío tenemos 
un tipo común que aparece en códices tanto los del Grupo Borgia como los mixtecas y los de tradición mexica. Como nos dicen las fuentes deben de haberse usado para llevar copal, pero también se guardaban en ellas otros objetos como puede verse por los dibujos del Códice Borbónico.

\section{BIBLIOGRAFÍA}

\section{Conex Borbonicus}

1974 "Codex Borbonicus". Codices Selecti, vol. XLIV, Akademische Druck-u. Verlagsanstalt, Graz, Austria.

Godex CospI

1968 "Codex Cospi". Codices Selecti, vol. XVIII, Akademische Druck-u. Verlagsanstalt, Graz, Austria.

CODEX FrjéRVÁRY-MAYER

1971 "Codex Fejérváry-Mayer", Codices Selecti, vol, XXVI, Akademische Druck-u. Verlagsanstalt, Graz, Austria.

\section{Codex Magliabecchiano}

1970 "Codex Magliabecchiano". Codices Selecti, vol. XXIII, Akademische Druck-u. Verlagsanstalt, Graz, Austria.

CODEX NutTalL

1975. The Codex Nuttall Zelia Nuttall, ed Dover Publications, New York

Godex Vaticanus 3773

1972 "Codex Vaticanus 3773" "Codices Selecti, vol XXXVI, Akademische Druck-u.. Verlagsanstalt, Graz, Austria.

Codex Vindobonensis

1963 Codex Vindobonensis Mexicanus 1. Akademische Druck-u-Verlagsanstalt, Graz, Austria.

Códice Laud

1964 "Códice Laud". Antigüedades de México basadas en la recopilación de Lord Kingsborough, vol 1, México, Sría de Hacienda y Grédito Público.

Códice Mendocino

1964 "Códice Menảocino". Antigüedades de México basadas en la recopilación de Lord Kingsborough, vol 1, México, Sría, de Hacienda y Cré.. dito Público.

\section{Códice Telieriano Remensis}

1964 "Códice Telleriano Remensis". Antigüedades de México basadas en ia recopilación de Lord Kingsborough, vol. 1, México, Sría. de Hacienda y Crédito Público. 
Códice Vaticino A

1964 "Códice Vaticano A". Antigiiedades de México basadas en la recopilación de Lord Kingsborough, vol 3, Secretaría de Hacienda y Crédito Público.

GendRop, P

1971 "Murales Prehispánicos". Artes de México, año XVIII, núm. 144, México.

GreEN, M. R. Rands y J Graham

1972. Maya Sculpture. Berkeley, California.

KAMPEN, M.

1972 The Sculptures of El Tajín, Veracruz, México. University of Florida Press, Florida.

Marcus, J.

1976 "The Iconography of Miliarism at Monte Albán and Neighboring Sites in the Valleys of Oaxaca". Origins of Religious Art and Iconography in Preclassic Mesoamerica, pp. 123-140, Los Angeles.

Miller, A. G.

1973 The Mural Painting of Teotihuacan. Dumbarton Oaks, Washington.

PADDOCK, J., ed.

1966 Ancient Oaxaca. Stanford University Press, Stanford, California.

Proskouriakof,$T_{\text {. }}$

1950 "A Study of Classic Maya Sculpture". Carnegie Institution of Washingion, Püb. 593, Washington.

SÉJOURNÉ, L.

1959 Un palacio en la ciudad de los dioses. INAH, México.

1966 Arquitectura y pintura en Teotihuacan. Ed. Siglo Veintiuno, México. 


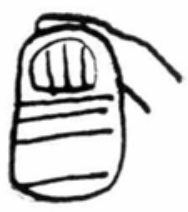

a

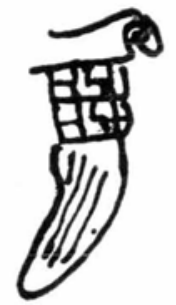

ch

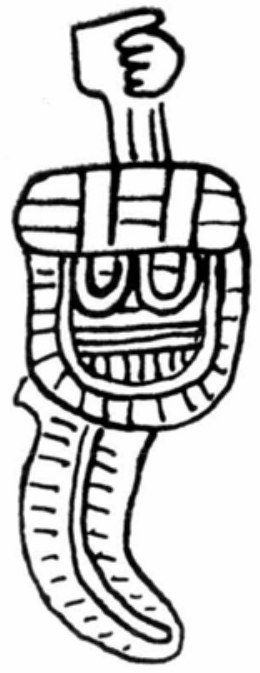

$b$
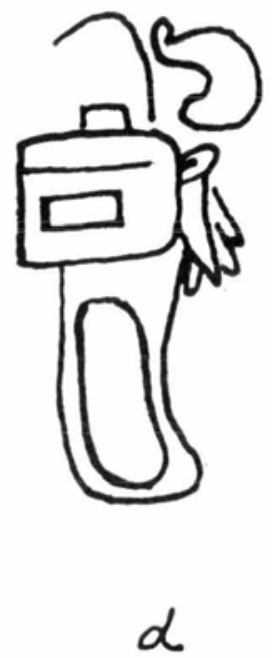

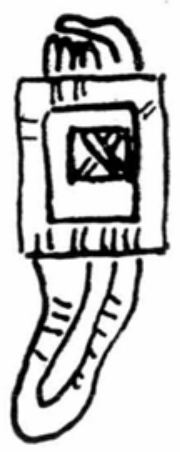

$c$

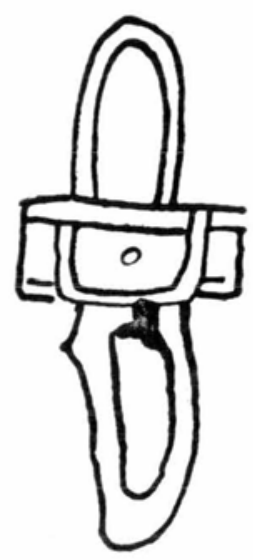

e

Lámina 1. a) Monumento 19 de La Venta. b) Relieve de la Pirámide de los Nichos.

c) Tablero 6 del Juego de Pelota. $c h$ ) Estela 4 de Cerro de Las Mesas. $d$ ) Pintura de Las Higueras. e) Pintura de Las Higueras. 


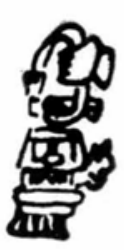

a

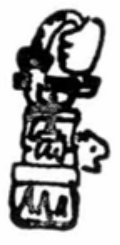

b

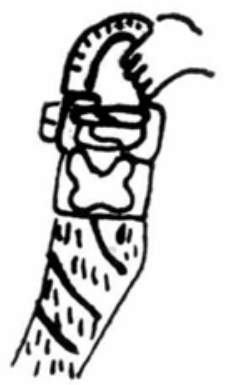

C

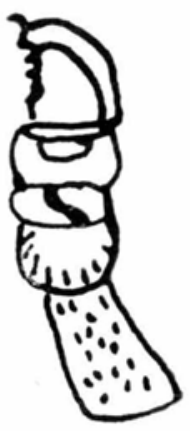

$d$

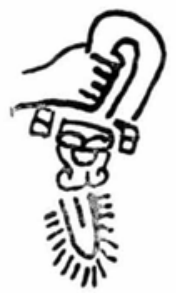

$f$

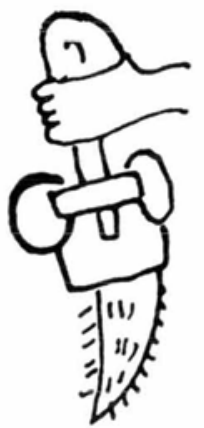

9

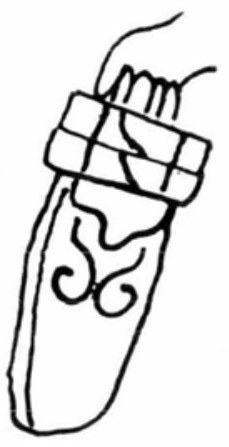

h

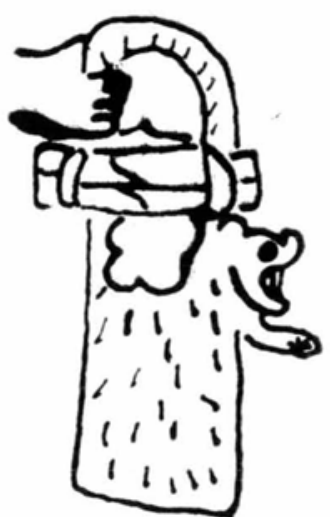

ch
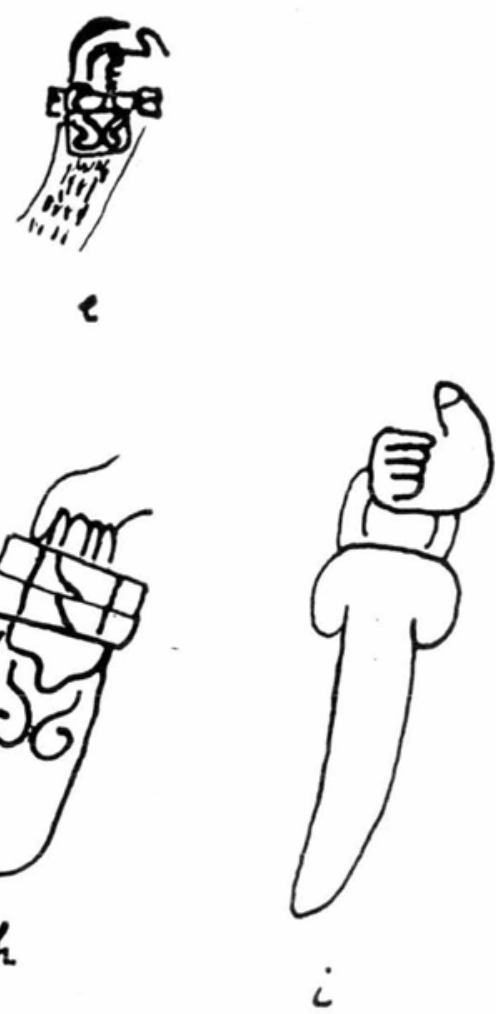

Lámina 2. a) Mural 3, Cuarto 2, Tepantitla. b) Mural 2, Cuarto 2, Tepantitla. c) Mural del Palacio de Zacuala. ch) Mural 3, Pórtico 1, Tetitla. d) Patio norte de la plaza de la Pirámide del Sol. $e$ ) Mural de la estructura este de la Pirámide de la Luna. f) Lápida de Bazán. g) Mural de la tumba 104 de Monte Albán. $h$ ) Relieve de Macuilxóchitl. i) Tumba de Zaachila. 


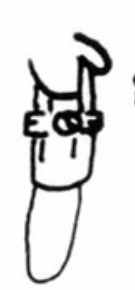

$a \quad b \quad c$

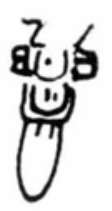

c
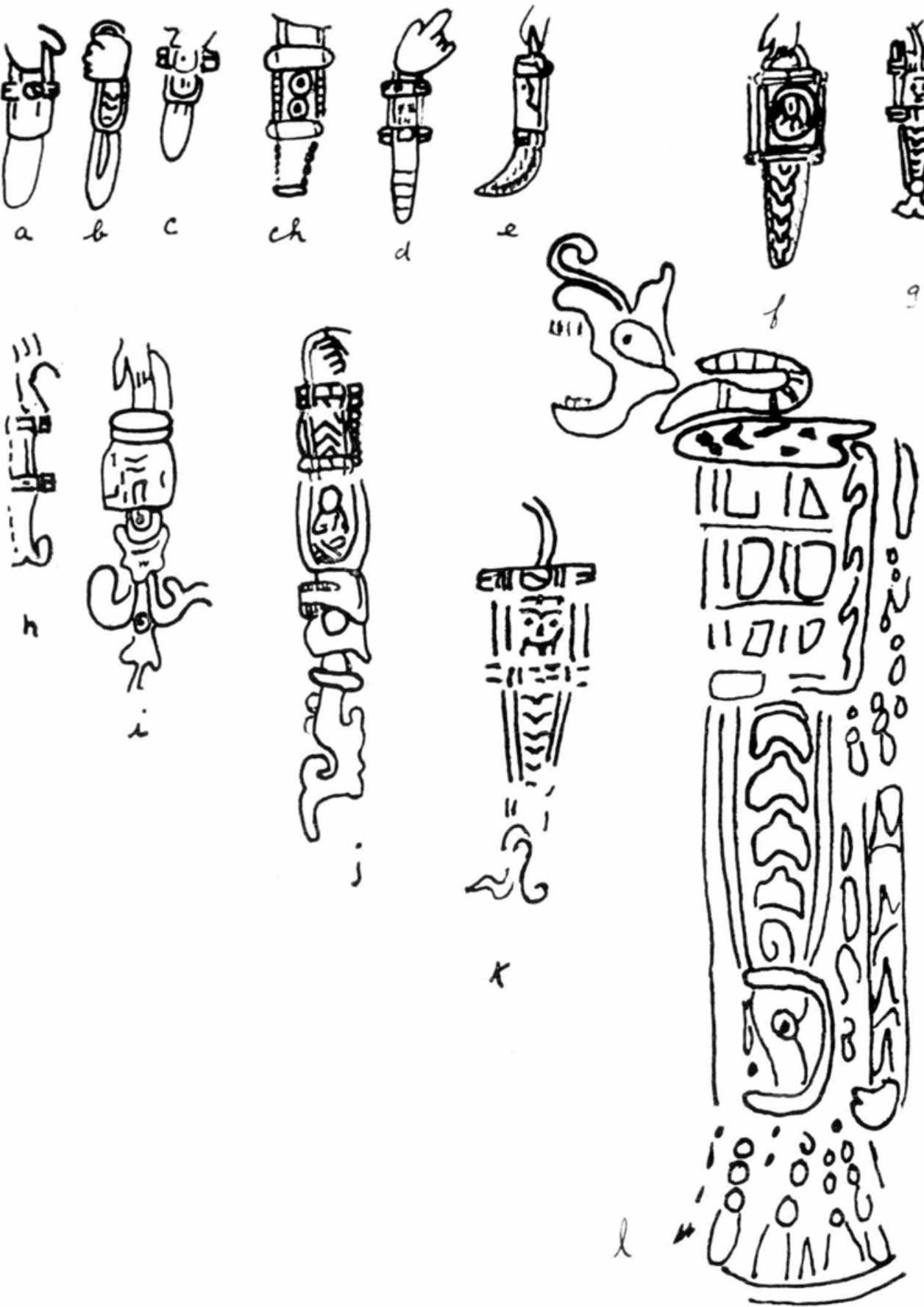

Lámina 3. a) Tikal estela 13. b) Yaxha estela 6. c) Piedras Negras estela 25. ch) Motul de San José, estela 2. d) Tikal, estela 16. e) Piedras Negras estela 40. f) Piedras Negras estela 13. g) Yaxchilán, estela 18. h) Cancuén, estela 2. i) Seibal, estela 1. j) Halan dintel (los anteriores son según Proskouriakoff, 1950) . k) Yaxchilán estela 18. $l$ ) Bonampak estela 3. 

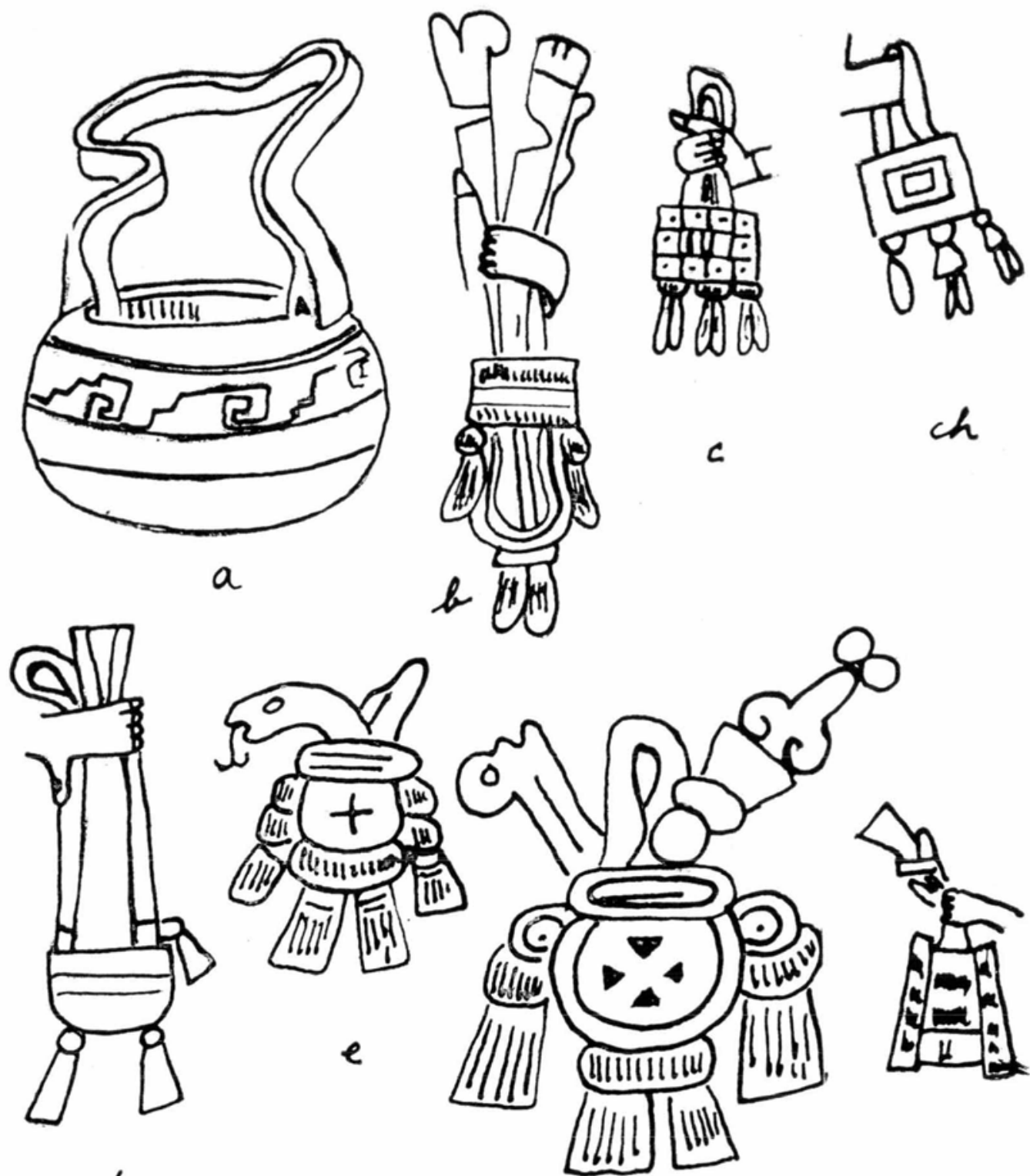

\&

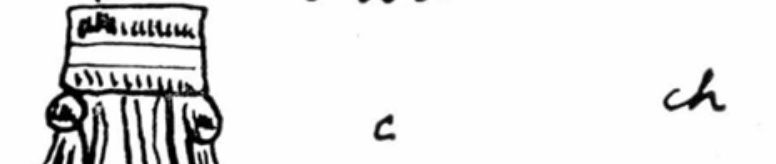

$d$ 


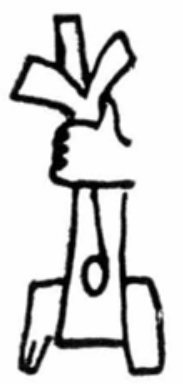

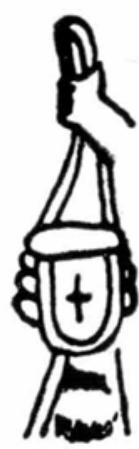

$b$

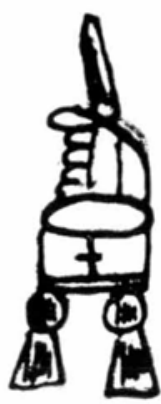

C

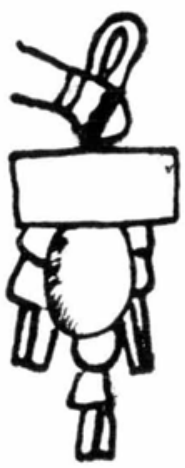

9

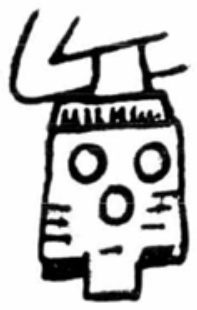

j

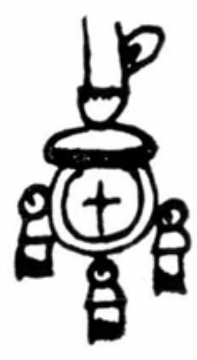

f
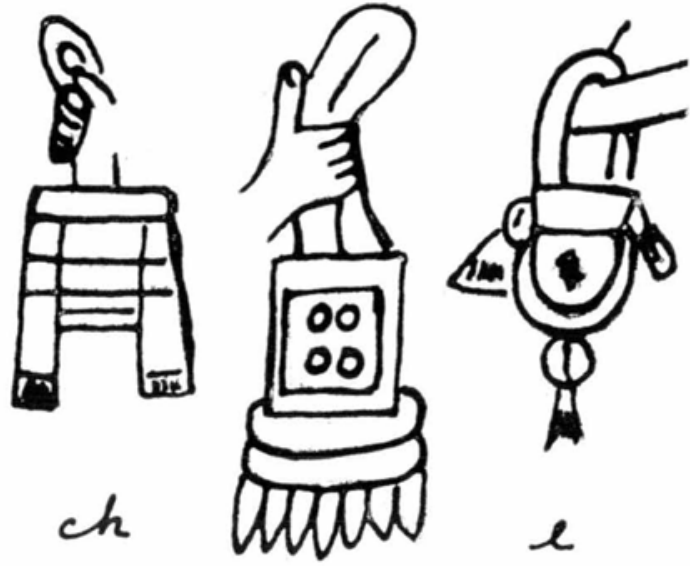

ch

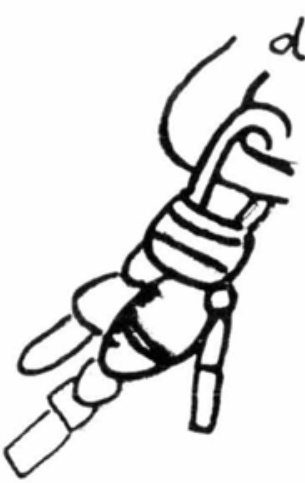

$h$

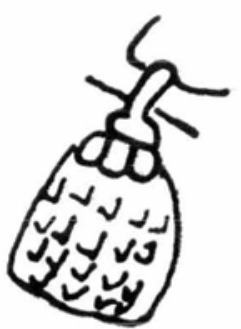

$\ell$

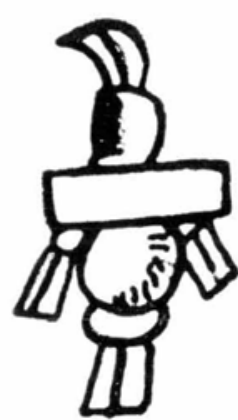

i

Lámina 5. a) Códice Vaticano A lámina XXVIII. b) Códice Vaticano A lámina XLVIII. c) Tonalámatl de Aubin. ch) Códice Magliabccchi. d) Códice Magliabecchi. e) Códice Magliabecchi. f) Códice Mendocino, lámina 63. g) Códice Nuttall, lámina 15. h) Códice Nuttall lámina 15. i) Códice Vindobonensis lámina 2. j) Lápida de la dedicación del Templo Mayor. $k$ ) Teocalli de la Guerra Sagrada. l) Caja del Museo Nacional de Antropologia. $m$ ) Caja del Museum of the American Indian. 